\title{
Soja em sucessão a adubos verdes no sistema de plantio direto e convencional em solo de Cerrado
}

\author{
Marco Antonio Camillo de Carvalho(1), Manoel Luiz Ferreira Athayde(2), Rogério Peres Soratto ${ }^{(3)}$, \\ Marlene Cristina Alves ${ }^{(4)}$ e Orivaldo Arf ${ }^{(4)}$
}

\begin{abstract}
(1)Universidade do Estado de Mato Grosso, Rodovia MT 208, Km 147, Caixa Postal 324, CEP 78580-000 Alta Floresta, MT. E-mail: marcocarva@bol.com.br (2)Universidade Estadual Paulista (Unesp), Fac. de Ciências Agrárias e Veterinárias, Via de Acesso Prof. Paulo Donato Castellane, s/no , CEP 14884-900 Jaboticabal, SP. (3)Unesp, Fac. de Ciências Agronômicas, Caixa Postal 237, CEP 18603-970 Botucatu, SP. E-mail: soratto@fca.unesp.br (4)Unesp, Fac. de Engenharia, Caixa Postal 31, CEP 15385-000 Ilha Solteira, SP. E-mail: mcalves@agr.feis.unesp.br, arf@agr.feis.unesp.br
\end{abstract}

Resumo - A adubação verde é uma prática em que se procura preservar a qualidade do ambiente sem prescindir de produtividades elevadas das culturas e do retorno econômico. $\mathrm{O}$ objetivo deste trabalho foi avaliar o desempenho da cultura da soja em sucessão a adubos verdes nos sistemas de plantio direto e de preparo convencional do solo (uma gradagem pesada + duas gradagens leves). O experimento foi realizado num Latossolo Vermelho distrófico, originalmente sob vegetação de Cerrado em Selvíria, MS. Utilizaram-se quatro adubos verdes: mucunapreta, guandu, crotalária e milheto, e área de pousio (vegetação espontânea). O cultivo de diferentes adubos verdes na primavera não influencia a produtividade da soja em sucessão, tanto em plantio direto quanto no sistema de preparo convencional do solo. Em ano com precipitação normal, o preparo convencional do solo proporciona maior produtividade da soja do que o sistema de plantio direto.

Termos para indexação: Glycine max, cultivo seqüencial, adubo orgânico, manejo do solo.

\section{Soybean grown after green manures under no-tillage and conventional management systems in savannah soil}

\begin{abstract}
The green manures aim to preserve the environment quality without discarding the largest yield of economic crops. The objective of this work was to evaluate the performance of soybean grown after green manures under no-tillage and conventional tillage (one disk harrow + two leveling harrow) systems. The experiment was carried out in a Distrophic Red Latossol (typic Hapludox), covered by savannah vegetation, in Selvíria, MS, Brazil. The green manures utilized were: black velvet bean, pigeon pea, sunn hemp, millet and fallow area (spontaneous vegetation). The green manures previously grown in spring do not affect the soybean yield, in both no-tillage and conventional tillage systems. In year without dry periods, the conventional tillage provided greater grain yield.
\end{abstract}

Index terms: Glycine max, sequential cropping, organic fertilizers, soil management.

\section{Introdução}

A sustentabilidade dos agrossistemas é diretamente influenciada pela forma de manejo dos solos e das culturas (Hernani et al., 1997). Na região dos Cerrados, onde os solos ficam expostos à intensa radiação solar e à erosão eólica durante a entressafra, e à erosão causada pelas chuvas intensas, comuns no início da estação chuvosa, a utilização de plantas para adubação verde e cobertura do solo assume importância significativa.

A sucessão de cultivos distintos contribui para a manutenção do equilíbrio dos nutrientes no solo e para o aumento da sua fertilidade, além de permitir melhor utilização dos insumos agrícolas. A adição regular de re- síduos de adubos verdes aos vários solos e ambientes agroecológicos dos trópicos contribui com a conservação do solo e da água, promovendo, principalmente, a melhoria da estrutura que favorece a aeração e a infiltração de água no solo, permitindo uma maior penetração das raízes (Lal, 1986). Além disso, propicia melhor aproveitamento de adubos químicos e redução nos custos com adubação mineral, uma vez que promove aumento da atividade biológica do solo (Hernani et al., 1995). Assim, o uso combinado de adubos minerais e de adubação verde constitui uma prática de manejo em que se procura preservar a qualidade ambiental sem prescindir da elevada produtividade das culturas (Arf et al., 1999). 
Existem evidências de que o aumento do teor de matéria orgânica do solo pode reduzir substancialmente as perdas de produtividades das culturas decorrentes do ataque de nematóides (Johnson, 1962). Adubos verdes como mucuna-preta e Crotalaria juncea podem controlar, também, plantas daninhas. Contudo, a resposta das culturas depende da interação de fatores como a natureza do material (relação $\mathrm{C} / \mathrm{N}$, teor de lignina), das propriedades do solo, das características da cultura principal e do clima (Lal, 1986; Amabile et al., 1994). A utilização de mucuna-preta, crotalária, guandu e lablab como adubo verde possibilitou aumentos significativos na produtividade do feijão e da soja (Tanaka et al., 1992; Wutke et al., 1998).

O preparo do solo tem como objetivo principal a melhoria das suas propriedades químicas, físicas e biológicas, visando aumentar o seu potencial produtivo. No entanto, o uso intensivo do solo pode predispô-lo à formação de camadas compactadas, à redução da estabilidade dos agregados e ao aparecimento, em maior número, de microporos, aumentando a propensão à perda de solo (Souza, 1988). Entre as conseqüências diretas da compactação do solo estão as reduções da porosidade e da infiltração de água e o aumento da resistência à penetração de raízes (Kirkegaard et al., 1993), com efeitos sobre sua distribuição e morfologia (Silva \& Rosolem, 2002).

Uma das estratégias para amenizar os efeitos da compactação é o cultivo de espécies com sistema radicular vigoroso, as quais estabelecem canais que favorecem o desenvolvimento de raízes da cultura subseqüente (Wang et al., 1986). Assim, a adubação verde tem sido tema de pesquisas que buscam mostrar sua viabilidade e solucionar problemas de manejo (De-Polli \& Chada, 1989). Para otimizar o uso da adubação verde, é necessário identificar as espécies mais adaptáveis à região, e adequá-las à melhor forma de manejo (Ceretta et al., 1994).

Outro aspecto de manejo da adubação verde, também carente de informações, é a necessidade ou não de sua incorporação ao solo (De-Polli \& Chada, 1989).

O objetivo deste trabalho foi avaliar o desempenho da cultura da soja em sucessão a adubos verdes no sistema de plantio direto e preparo convencional do solo (uma gradagem pesada + duas gradagens leves).

\section{Material e Métodos}

O experimento foi realizado nos anos agrícolas de 1997/1998 e 1998/1999, na área experimental da Facul- dade de Engenharia de Ilha Solteira - Unesp, no Município de Selvíria, MS (51²2' W e 20²2' S; 335 m de altitude). O solo do local é um Latossolo Vermelho distrófico típico argiloso, A moderado, hipodistrófico, álico, caulinítico, férrico, compactado, muito profundo, moderadamente ácido (Embrapa, 1999). O clima, conforme a classificação de Köppen, é do tipo Aw, com precipitação média anual de $1.370 \mathrm{~mm}$, concentrada, principalmente no período de outubro a março, temperatura média anual de $23,5^{\circ} \mathrm{C}$ e umidade relativa do ar entre $70 \%$ e $80 \%$. As precipitações pluviais registradas durante o período experimental são mostradas na Figura 1.

Antes da instalação do experimento, foi coletada amostra composta de 10 subamostras de solo $(0-0,20 \mathrm{~m})$ da área experimental, cujas características químicas foram as seguintes: matéria orgânica, $27,0 \mathrm{~g} \mathrm{dm}^{-3} ; \mathrm{pH}\left(\mathrm{CaCl}_{2}\right), 5,3 ; \mathrm{P}, 13,0 \mathrm{mg} \mathrm{dm}^{-3} ; \mathrm{K}, \mathrm{Ca} \mathrm{e}$ $\mathrm{Mg}, 1,1,28,0$ e $10,3 \mathrm{mmol}_{\mathrm{c}} \mathrm{dm}^{-3}$, respectivamente, e saturação por bases, $57 \%$.

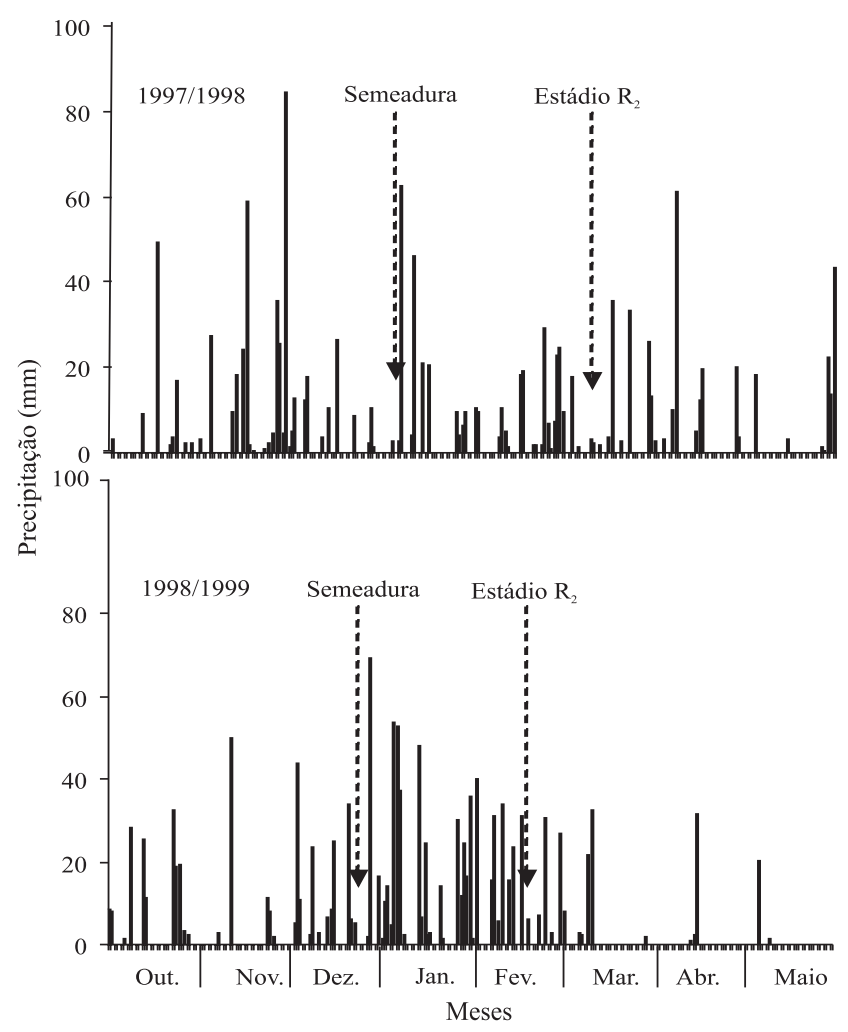

Figura 1. Precipitação pluvial $\left(\mathrm{mm} \mathrm{dia}^{-1}\right)$ da área experimental durante o período de outubro a maio, nos anos agrícolas de 1997/1998 e 1998/1999, e datas em que a soja atingiu o estádio $\mathrm{R}_{2}$ (florescimento pleno) da escala de Fehr \& Caviness (1977). Selvíria, MS. 
O delineamento experimental utilizado foi em blocos ao acaso com parcelas subdivididas e quatro repetições. As parcelas foram constituídas por quatro adubos verdes: mucuna-preta (Mucuna aterrima (Piper \& Tracy) Merr.), guandu (Cajanus cajan (L.) Millsp.), crotalária (Crotalaria juncea L.), milheto (Pennisetum americanum L.) e área de pousio (vegetação espontânea). Na área em pousio, predominavam espécies como Panicum maximum (Jacq.) e Brachiaria decumbens (Stapf.) Prain. As subparcelas foram constituídas pelos dois sistemas de manejo do solo: plantio direto (semeadura sem preparo prévio do solo) e sistema de preparo convencional (preparo do solo com grade pesada à profundidade de $0,15-0,20 \mathrm{~m}$ ), e em seguida foram feitas duas gradagens com grade leve à profundidade de 0,10-0,12 m. Cada subparcela teve a dimensão de $7 \mathrm{x} 6 \mathrm{~m}$, espaçadas umas das outras por $7 \mathrm{~m}$.

O solo da área experimental, originalmente sob vegetação de cerrado, foi cultivado desde 1978 com milho, feijão e arroz, no sistema convencional, realizando-se no máximo dois cultivos por ano agrícola. Na safra de verão do ano agrícola 1996/1997, foi utilizada a cultura do arroz. Para instalação da cultura de inverno, o solo foi preparado mediante uma aração, com arado de discos reversíveis e tração motorizada, à profundidade de $0,20-0,25 \mathrm{~m}$ e duas gradagens, com grade leve à profundidade de $0,10-0,12 \mathrm{~m}$. A primeira gradagem foi feita após a aração (30/4/1997) e a segunda, antes da semeadura do feijão de inverno (15/5/1997), para a uniformização da área. Em outubro de 1997, nas áreas destinadas ao plantio direto, foi aplicado o herbicida glifosate (2.400 $\mathrm{g} \mathrm{ha}^{-1}$ do i.a.). O restante da área recebeu preparo de solo convencional (uma gradagem pesada + duas gradagens leves).

A semeadura dos adubos verdes foi realizada mecanicamente em 19/10/1997 e 8/10/1998, em sucessão ao feijoeiro de inverno. O espaçamento e densidade de semeadura utilizados foram os seguintes: $0,45 \mathrm{~m}$ entrelinhas e cinco sementes por metro para mucuna-preta; $0,45 \mathrm{~m}$ entrelinhas e 30 sementes por metro para crotalária e guandu, e 0,225 m entrelinhas e 120 sementes por metro para milheto. Todas as espécies foram semeadas sem a utilização de adubação básica ou de cobertura. Em 17/12/1997 e 21/12/1998, avaliou-se a produção de matéria seca (MS) da parte aérea, coletando-se, aleatoriamente, duas subamostras de $1,0 \mathrm{~m}^{2}$ por subparcela, para formarem uma única amostra. $\mathrm{O}$ material coletado foi secado em estufa a $65^{\circ} \mathrm{C}$ até peso constante e, a seguir, pesado.
Nas mesmas datas em que foram realizadas as avaliações da produção de MS, nas áreas destinadas ao sistema de plantio direto, a vegetação foi dessecada mediante aplicação de herbicida glifosate (2.400 $\mathrm{g} \mathrm{ha}^{-1}$ do i.a.), via pulverização tratorizada. Nas áreas destinadas ao sistema convencional, a vegetação foi roçada e o solo foi preparado com uma gradagem pesada e duas gradagens leves, conforme descrito anteriormente.

A soja foi semeada em 7/1/1998 e 28/12/1998, mecanicamente, utilizando-se a cultivar IAC 17 na safra 1997/98 e FT Cristalina na safra 1998/99, com 25 sementes por metro de sulco e 0,45 m entrelinhas, com as sementes inoculadas com Bradyrhizobium japonicum. A adubação básica foi de $250 \mathrm{~kg} \mathrm{ha}^{-1}$ da fórmula NPK 8-28-16, nas duas safras. No cálculo da quantidade de fertilizante, foram levadas em consideração as características químicas do solo, a produtividade esperada (2,5 a 3,0 $\left.\mathrm{Mg} \mathrm{ha}^{-1}\right)$ e as recomendações de Raij et al. (1996).

No período outono-inverno de 1998, a área experimental foi cultivada com a cultura do feijão após a colheita da soja, porém os sistemas de manejo do solo foram mantidos, em cada subparcela, de acordo com o estabelecido para os adubos verdes e para a soja. Nos tratamentos de plantio direto, o feijão foi semeado sobre os restos da cultura da soja.

$\mathrm{Na}$ avaliação da produtividade de grãos, foram colhidas em 15/5/1998 e 9/5/1999, as quatro linhas centrais de cada subparcela, perfazendo uma área útil de $9,0 \mathrm{~m}^{2}$. Nessa ocasião também foi determinada a população de plantas, contando-se as plantas contidas nas quatro linhas centrais de cada subparcela. Também foram coletadas dez plantas por unidade experimental e nelas foram determinados a altura de planta e de inserção da primeira vagem, o número total de vagens por planta, $o$ número médio de grãos por vagem e a massa de 100 grãos. A umidade dos grãos foi corrigida para $0,13 \mathrm{~kg} \mathrm{~kg}^{-1}$.

Antes da instalação do experimento em 1997 e após a colheita da cultura nos anos de 1998 e 1999, foi determinada a densidade do solo, em vinte pontos por unidade experimental, pelo método do anel volumétrico, nas profundidades de $0-0,1,0,1-0,2$ e $0,2-0,4 \mathrm{~m}$.

Os dados de produtividade de MS dos adubos verdes e das características da cultura da soja foram submetidos à análise de variância em cada ano agrícola. Quando não houve interação significativa entre os fatores, foram comparados apenas os efeitos isolados de cada fator. Posteriormente, para a produtividade de MS dos adubos verdes, realizou-se a análise conjunta dos dois 
anos agrícolas, uma vez que a razão entre o maior e o menor quadrado médio residual de cada ano não foi superior a sete, para verificar se houve efeito dos anos e das interações entre o ano agrícola e os demais fatores estudados (Banzatto \& Kronka, 1989). As médias foram comparadas pelo teste de Tukey a $5 \%$ de probabilidade. Nos dados da cultura da soja optou-se por não realizar a análise conjunta, uma vez que foram utilizadas cultivares diferentes nos dois anos agrícolas, o que poderia levar a interpretações equivocadas dos resultados.

\section{Resultados e Discussão}

A produtividade de matéria seca variou entre as espécies de adubos verdes (Tabela 1). Nos dois anos de cultivo e em ambos os sistemas de manejo do solo, o milheto se destacou, com produtividade média de 9.593 e $14.150 \mathrm{~kg} \mathrm{ha}^{-1}$, seguido da crotalária no primeiro ano e da mucuna-preta, no segundo. O guandu foi a espécie que produziu menor quantidade de matéria seca, tendo produtividade inferior até mesmo à área em pousio, onde predominavam espécies como Panicum maximum (Jacq.) e Brachiaria decumbens (Stapf.) Prain, no segundo ano agrícola.

O manejo dos adubos verdes ocorreu cerca de 60 dias após a emergência (DAE), ou seja, bem antes do florescimento. De acordo com Amabile et al. (2000), o florescimento de espécies como guandu, mucuna-preta e crotalária ocorre cerca de 120-140 DAE, quando semeados em novembro, na região Centro-Oeste. Entretanto, Wutke (1993) relatou que a produtividade de MS no Estado de São Paulo varia de 8 a $12 \mathrm{t} \mathrm{ha}^{-1}$ (guandu) e de 6 a 8 t ha $^{-1}$ (mucuna-preta), quando o manejo ocorre no florescimento pleno, em semeadura realizada na primavera. A semeadura do guandu em espaçamentos menores $(0,25 \mathrm{~m})$ poderia ter contribuído para o aumento da produtividade de matéria seca por área.

O manejo do solo influenciou a produtividade de matéria seca apenas no milheto, sendo que o sistema de plantio direto proporcionou produção significativamente superior nesta espécie nos dois anos de experimentação (Tabela 1). Segundo Alvarenga et al. (2001), o sistema de plantio direto propicia ambiente favorável ao estabelecimento das culturas. Além disso, fatores como temperatura e cobertura superficial do solo têm, em muitas situações, disponibilizado mais água às plantas em solos sob sistema de plantio direto, influenciando diretamente a economia de água, o desenvolvimento e a produtividade das culturas (Stone \& Silveira, 1999). A análise conjunta dos dados mostrou interação significativa apenas entre os adubos verdes e ano agrícola, sendo que apenas o milheto apresentou maior produtividade de MS no segundo ano (Tabela 1). A maior produtividade de MS do milheto, no segundo ano agrícola, pode estar relacionada ao fato de que esse cultivo foi realizado após a sucessão soja/feijão, o que pode ter acrescentado grande quantidade de $\mathrm{N}$ ao solo, favorecendo o crescimento do milheto. É sabido que as leguminosas, de modo geral, possuem capacidade de fixar $\mathrm{N}_{2}$ atmosférico em simbiose com Rhizobium, além de possuírem baixa relação $\mathrm{C} / \mathrm{N}$, o que favorece a rápida decomposição e liberação desse nutriente para a cultura sucessora (Ceretta et al., 1994).

A população de plantas sofreu efeito apenas do sistema de manejo do solo, nos dois anos de cultivo (Tabela 2). O sistema de plantio direto proporcionou melhor estabelecimento das plantas, provavelmente pelo fato de, nesse sistema, a palha remanescente sobre a área promover maior proteção do solo contra o impacto das gotas de chuva, durante o período que antecede a emergência das plantas, evitando a formação de uma crosta

Tabela 1. Produtividade de matéria seca da parte aérea $\left(\mathrm{kg} \mathrm{ha}^{-1}\right)$ dos adubos verdes e da vegetação espontânea da área em pousio, em sistema de plantio direto (PD) e preparo convencional (PC), nos anos agrícolas de 1997/1998 e 1998/1999(1).

\begin{tabular}{|c|c|c|c|c|c|c|}
\hline \multirow[t]{2}{*}{ Adubo verde } & \multicolumn{3}{|c|}{ 1997/1998 } & \multicolumn{3}{|c|}{$1998 / 1999$} \\
\hline & PD & $\mathrm{PC}$ & Média & $\mathrm{PD}$ & $\mathrm{PC}$ & Média \\
\hline Mucuna-preta & $4.916 \mathrm{bA}$ & 4.417abA & $4.666 a$ & $5.200 \mathrm{bA}$ & $7.400 \mathrm{bA}$ & $6.300 a$ \\
\hline Guandu & $3.350 \mathrm{bA}$ & $2.767 \mathrm{bA}$ & $3.058 a$ & $3.100 \mathrm{bA}$ & $2.400 \mathrm{cA}$ & $2.750 a$ \\
\hline Milheto & $11.357 \mathrm{aA}$ & $7.830 \mathrm{aB}$ & $9.593 b$ & $16.200 \mathrm{aA}$ & $12.105 \mathrm{aB}$ & $14.150 a$ \\
\hline Crotalária & $6.324 \mathrm{bA}$ & $5.836 \mathrm{abA}$ & $5.980 a$ & $3.950 \mathrm{bA}$ & $4.625 \mathrm{bcA}$ & $4.275 a$ \\
\hline Pousio & $5.811 \mathrm{bA}$ & $3.069 \mathrm{bA}$ & $4.440 a$ & $4.400 \mathrm{bA}$ & $6.235 \mathrm{bA}$ & $5.300 a$ \\
\hline Média & 6.352 & 4.351 & & 6.570 & 6.540 & \\
\hline
\end{tabular}

${ }^{(1)}$ Médias seguidas de mesmas letras, minúsculas nas colunas e maiúsculas nas linhas, dentro de cada ano agrícola, e em itálico para comparação entre os anos (análise conjunta), não diferem entre si pelo teste de Tukey a 5\% de probabilidade. 
superficial, já que nos dois anos agrícolas houve precipitações maiores que $60 \mathrm{~mm} \mathrm{dia}^{-1}$, logo após a semeadura (Figura 1). Além disso, a cobertura vegetal inerente a esse sistema de cultivo pode ter promovido menor perda de água e menores variações de temperatura do solo, favorecendo o estabelecimento da cultura (Salton \& Mielniczuk, 1995; Bortoluzzi \& Eltz, 2000). Centurion \& Demattê (1985) também verificaram maior população de plantas no sistema de plantio direto, quando comparado ao preparo convencional e atribuíram este fato às melhores condições de germinação e emergência proporcionadas por este sistema.

Entre os fatores que exercem influência direta nas perdas e na pureza dos grãos na colheita mecanizada estão a altura das plantas e, principalmente, a altura de inserção da primeira vagem (Medina, 1994). Assim, plantas com essas características, quando associadas à au- sência de acamamento, apresentam vantagens na colheita. Os adubos verdes não influenciaram a altura de plantas e a inserção da primeira vagem (Tabela 2 ).

O sistema convencional de preparo do solo favoreceu o desenvolvimento vegetativo da planta no primeiro ano de experimentação. Já em 1998/99, as plantas apresentaram maior altura no sistema de plantio direto. Porém, a altura de inserção da primeira vagem não foi influenciada pelo manejo do solo em nenhuma das safras.

Os adubos verdes não interferiram no número de vagens por planta nos dois anos agrícolas (Tabela 3). Já os sistemas de manejo do solo, tiveram efeito sobre essas variáveis. O sistema convencional de preparo do solo proporcionou a obtenção de maior número de vagens por planta e aumentou o número médio de grãos por vagem no primeiro ano agrícola. As diferenças obser-

Tabela 2. População final de plantas, altura de planta e altura de inserção da primeira vagem da soja cultivada em sucessão a adubos verdes, em plantio direto e preparo convencional do solo, nos anos agrícolas de 1997/1998 e 1998/1999(1).

\begin{tabular}{|c|c|c|c|c|c|c|}
\hline \multirow[t]{2}{*}{ Tratamentos } & \multicolumn{2}{|c|}{ População de plantas (plantas ha ${ }^{-1}$ ) } & \multicolumn{2}{|c|}{ Altura de planta $(\mathrm{cm})$} & \multicolumn{2}{|c|}{ Altura de inserção da primeira vagem $(\mathrm{cm})$} \\
\hline & $1997 / 1998$ & $1998 / 1999$ & 1997/1998 & $1998 / 1999$ & $1997 / 1998$ & $1998 / 1999$ \\
\hline & \multicolumn{6}{|c|}{ Adubo verde } \\
\hline Mucuna-preta & 137.700 & 178.900 & 57,10 & 96,80 & 13,90 & 15,20 \\
\hline Guandu & 156.400 & 177.900 & 54,00 & 97,20 & 12,30 & 17,10 \\
\hline Milheto & 136.400 & 172.000 & 60,50 & 97,40 & 15,90 & 13,50 \\
\hline Crotalária & 149.100 & 131.500 & 57,50 & 89,00 & 11,80 & 14,70 \\
\hline Pousio & 133.300 & 184.500 & 57,00 & 96,30 & 12,10 & 14,50 \\
\hline \multirow[t]{2}{*}{$\mathrm{CV}(\%)$} & 18,40 & 23,70 & 11,80 & 10,20 & 25,40 & 28,30 \\
\hline & \multicolumn{6}{|c|}{ Sistema de manejo } \\
\hline Plantio direto & $189.500 \mathrm{a}$ & $200.000 \mathrm{a}$ & $53,30 \mathrm{~b}$ & $109,70 \mathrm{a}$ & 12,70 & 15,10 \\
\hline Preparo convencional & $195.700 \mathrm{~b}$ & $138.000 \mathrm{~b}$ & $61,20 \mathrm{a}$ & $81,00 \mathrm{~b}$ & 13,70 & 15,00 \\
\hline$\overline{\mathrm{CV}}(\%)$ & 29,80 & 23,80 & 7,70 & 9,80 & 26,60 & 16,30 \\
\hline
\end{tabular}

${ }^{(1)}$ Médias seguidas de letras distintas na coluna, para cada fator, diferem entre si pelo teste de Tukey a 5\% de probabilidade.

Tabela 3. Número de vagens por planta, grãos por vagem, massa de 100 grãos e produtividade de grãos de soja cultivada em sucessão a adubos verdes, em plantio direto e preparo convencional do solo, nos anos agrícolas de 1997/1998 e 1998/1999(1).

\begin{tabular}{|c|c|c|c|c|c|c|c|c|}
\hline \multirow[t]{2}{*}{ Tratamentos } & \multicolumn{2}{|c|}{$\begin{array}{l}\text { Número de vagens } \\
\text { por planta }\end{array}$} & \multicolumn{2}{|c|}{$\begin{array}{l}\text { Número de grãos } \\
\text { por vagem }\end{array}$} & \multicolumn{2}{|c|}{$\begin{array}{l}\text { Massa de } 100 \text { grãos } \\
\text { (g) }\end{array}$} & \multicolumn{2}{|c|}{$\begin{array}{l}\text { Produtividade de grãos } \\
\qquad\left(\mathrm{kg} \mathrm{ha}^{-1}\right)\end{array}$} \\
\hline & $1997 / 1998$ & $1998 / 1999$ & $1997 / 1998$ & $1998 / 1999$ & $1997 / 1998$ & $1998 / 1999$ & $1997 / 1998$ & $1998 / 1999$ \\
\hline & \multicolumn{8}{|c|}{ Adubo verde } \\
\hline Mucuna-preta & 70,50 & 92,90 & 1,47 & 1,09 & 16,70 & 17,50 & 2.079 & 2.794 \\
\hline Guandu & 68,80 & 111,80 & 1,32 & 0,87 & 16,00 & 16,80 & 1.726 & 2.519 \\
\hline Milheto & 68,80 & 96,90 & 1,33 & 1,06 & 15,30 & 16,10 & 1.613 & 2.773 \\
\hline Crotalária & 78,80 & 108,20 & 1,36 & 1,04 & 16,00 & 16,80 & 1.947 & 2.251 \\
\hline Pousio & 68,50 & 92,40 & 1,27 & 0,99 & 16,40 & 17,20 & 1.494 & 2.636 \\
\hline \multirow[t]{2}{*}{$\mathrm{CV}(\%)$} & 23,10 & 23,90 & 14,30 & 13,40 & 7,10 & 9,60 & 29,50 & 19,70 \\
\hline & \multicolumn{8}{|c|}{ Sistema de manejo } \\
\hline Plantio direto & $48,20 \mathrm{~b}$ & $81,30 \mathrm{~b}$ & $1,09 \mathrm{~b}$ & 1,07 & 16,40 & 17,30 & $1.571 \mathrm{~b}$ & 2.754 \\
\hline$\underline{\text { Preparo convencional }}$ & $93,90 \mathrm{a}$ & $119,50 \mathrm{a}$ & $1,62 \mathrm{a}$ & 0,95 & 15,70 & 16,50 & $1.973 \mathrm{a}$ & 2.435 \\
\hline $\mathrm{CV}(\%)$ & 35,40 & 18,90 & 11,10 & 11,00 & 12,90 & 11,00 & 32,20 & 20,80 \\
\hline
\end{tabular}

${ }^{(1)}$ Médias seguidas de letras distintas na coluna, para cada fator, diferem entre si pelo teste de Tukey a $5 \%$ de probabilidade. 
vadas estão intimamente relacionadas com a população de plantas, pois a soja possui a capacidade de compensar o baixo estande, com maior desenvolvimento das plantas (ramificações laterais), as quais terão maior número de vagens e estas apresentarão maior quantidade de grãos, conseqüentemente, assim compensando na produtividade final (Yusuf et al., 1999).

O revolvimento do solo, mediante o preparo convencional, pode ter favorecido o desenvolvimento radicular da cultura da soja, permitindo uma melhor exploração do solo e maior absorção de nutrientes e água, já que diminuiu a densidade, principalmente, na camada superficial do solo (Tabela 4). Rosolem et al. (1994) observaram que a compactação do solo reduziu significativamente o crescimento radicular, mas não afetou a parte aérea da soja. Mesmo em solo com densidade que prejudique o crescimento radicular, o efeito na parte aérea depende também da umidade do solo (Johnson et al., 1990) e da sua capacidade em fornecer nutrientes (Marschner, 1986). Dessa forma, a incorporação proporcionada pelo preparo do solo pode ter acelerado o processo de decomposição dos resíduos vegetais e liberação de nutrientes. De-Polli \& Chada (1989) verificaram que a incorporação da vegetação da entressafra ao solo, em vez de deixá-la em cobertura, propiciou maior produtividade do milho.

Quanto ao número médio de grãos por vagem, no primeiro ano agrícola, houve efeito apenas do sistema de manejo do solo, com o sistema de preparo convencional proporcionando maior valor desta variável (Tabela 3). Em 1998/1999 houve efeito da interação adubo verde x sistema de manejo em relação ao número mé-

Tabela 4. Densidade do solo $\left(\mathrm{Mg} \mathrm{m}^{-3}\right)$ em razão dos sistemas de manejo, nas diferentes camadas, antes da instalação do experimento em 1997 e após a colheita da cultura da soja nos anos de 1998 e $1999^{(1)}$.

\begin{tabular}{|c|c|c|c|}
\hline \multirow[t]{2}{*}{ Sistema de manejo do solo } & \multicolumn{3}{|c|}{ Ano } \\
\hline & 1997 & 1998 & 1999 \\
\hline & \multicolumn{3}{|c|}{----------- $(0,0-0,1 \mathrm{~m})$----------- } \\
\hline Plantio direto & $1,57 \mathrm{a}$ & $1,60 \mathrm{a}$ & $1,65 \mathrm{a}$ \\
\hline \multirow[t]{2}{*}{ Preparo convencional } & $1,44 b$ & $1,44 \mathrm{~b}$ & $1,38 \mathrm{~b}$ \\
\hline & \multicolumn{3}{|c|}{ 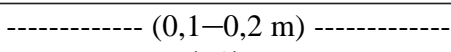 } \\
\hline Plantio direto & 1,56 & 1,61 & 1,61 \\
\hline \multirow[t]{2}{*}{ Preparo convencional } & 1,54 & 1,60 & 1,59 \\
\hline & \multicolumn{3}{|c|}{---------- $(0,2-0,4$ m) --------. } \\
\hline Plantio direto & 1,35 & 1,40 & 1,40 \\
\hline Preparo convencional & 1,32 & 1,36 & 1,38 \\
\hline
\end{tabular}

${ }^{(1)}$ Médias seguidas de letras distintas, nas colunas, dentro de cada profundidade, diferem entre si pelo teste de Tukey a 5\% de probabilidade. dio de grãos por vagem (Tabela 5). No sistema de plantio direto não houve efeito dos adubos verdes, porém no sistema de preparo convencional a incorporação do milheto proporcionou maior número de grãos por vagem, em relação ao guandu.

Os resultados podem ser explicados pelo fato de o milheto ter produzido maior quantidade de matéria seca, que ao ser incorporada, pode ter melhorado as condições do solo. Segundo De-Polli \& Chada (1989) e Tanaka et al. (1992), a adição de matéria orgânica, por meio da adubação verde, causa modificações nas propriedades físicas, químicas e biológicas do solo. Entretanto, nos tratamentos com mucuna-preta e guandu, o sistema de preparo convencional proporcionou menor número de grãos por vagem, em comparação com o plantio direto, provavelmente por ter promovido, de modo geral, maior número de vagens por planta (Tabela 3). Além disso, Tanaka et al. (1992) verificaram redução na produtividade da soja quando cultivada após guandu e atribuíram esse comportamento ao fato de o guandu ser suscetível a nematóides do gênero Meloidogyne, que também atacam a soja.

A massa de 100 grãos não foi influenciada pelos fatores estudados (Tabela 3). Entre os componentes da produção, a massa de 100 grãos de soja é o que apresenta a menor variação percentual decorrente de alterações no ambiente de cultivo. Assim, em condições de restrição hídrica, a planta de soja preferencialmente formará poucos grãos nas vagens fixadas, ao invés de muitos e malformados, pois o objetivo biológico principal é a perpetuação da espécie (Lima, 2001).

A produtividade de grãos não foi influenciada pelos adubos verdes utilizados (Tabela 3). Tanaka et al. (1992), ao contrário, obtiveram incrementos na produtividade de soja, principalmente após a incorporação de leguminosas como a crotalária e a mucuna-preta e atribu-

Tabela 5. Efeito da interação entre adubo verde e sistema de manejo do solo referente ao número médio de grãos por vagem. Ano agrícola de 1998/1999(1).

\begin{tabular}{lcc}
\hline Adubo verde & \multicolumn{2}{c}{ Sistema de manejo } \\
\cline { 2 - 3 } & Plantio direto & Preparo convencional \\
\hline Mucuna-preta & $1,20 \mathrm{aA}$ & $0,99 \mathrm{abB}$ \\
Guandu & $0,98 \mathrm{aA}$ & $0,76 \mathrm{bB}$ \\
Milheto & $1,07 \mathrm{aA}$ & $1,05 \mathrm{aA}$ \\
Crotalária & $1,11 \mathrm{aA}$ & $0,97 \mathrm{abA}$ \\
Pousio & $1,02 \mathrm{aA}$ & $0,97 \mathrm{abA}$ \\
\hline
\end{tabular}

(1)Médias seguidas de letras distintas, minúsculas nas colunas e maiúsculas nas linhas, diferem entre si pelo teste de Tukey a 5\% de probabilidade. 
íram tais resultados à redução da população de nematóides fitopatogênicos, ocasionada pelo cultivo dessas espécies de adubos verdes. O sistema de preparo convencional do solo propiciou maior produtividade de grãos, no primeiro ano agrícola. Os resultados evidenciam a grande capacidade compensatória da planta de soja, que apesar de ter apresentado população de plantas bastante inferior no sistema de preparo convencional, em relação ao plantio direto, apresentou maior produtividade de grãos, por causa do aumento no número de vagens por planta e de grãos por vagem. Outro fator que pode ter contribuído para a maior produtividade no sistema de preparo convencional foi a menor densidade do solo resultante desse sistema, que pode ter proporcionado maior crescimento radicular e absorção de água e nutrientes (Tabela 4). Segundo Rosolem et al. (1994) e Silva \& Rosolem (2002), a compactação do solo reduz o crescimento radicular da soja.

Em 1998/1999, não houve efeito do sistema de manejo na produtividade de grãos (Tabela 3). Esse resultado pode ser explicado pelo fato de que, apesar do preparo convencional ter diminuído a compactação do solo, provavelmente proporcionou condições mais favoráveis ao desenvolvimento do sistema radicular e ao aumento do número de vagens por planta. A permanência de cobertura vegetal sobre o solo, promovida pelo sistema de plantio direto, pode ter contribuído para minimizar os efeitos dos veranicos que ocorreram durante as fases de formação da vagem e enchimento de grãos (Figura 1). Segundo Santos et al. (1995), sob condições de baixa precipitação, o sistema de plantio direto é mais eficiente na manutenção da umidade disponível do solo, principalmente por causa da permanência de palhada na superfície. Kluthcouski et al. (2000) não verificaram diferença na produtividade da soja sob plantio direto ou preparo convencional (grade pesada + grade leve), porém, mesmo sob sistema de plantio direto, a densidade do solo não ultrapassou $1,23 \mathrm{Mg} \mathrm{m}^{-3}$, bem abaixo do observado no presente trabalho.

A baixa produtividade média, obtida principalmente no primeiro ano agrícola $\left(1.771 \mathrm{~kg} \mathrm{ha}^{-1}\right)$, comparada à produtividade de $3.558 \mathrm{~kg} \mathrm{ha}^{-1}$ verificada em sistema de plantio direto e convencional por Kluthcouski et al. (2000), e $2.304 \mathrm{~kg} \mathrm{ha}^{-1}$, por Mascarenhas et al. (1993), em estudo de sistemas de rotação de culturas, pode estar relacionada ao fato de a semeadura ter sido realizada em época considerada tardia (7/1/1998).

\section{Conclusões}

1. O cultivo de adubos verdes na primavera não influencia a produtividade da soja em sucessão, tanto quando deixados sobre o solo, em plantio direto, como quando incorporados no sistema de preparo convencional do solo.

2. O sistema convencional de preparo do solo (grade pesada + grade leve) proporciona maior produtividade da soja em ano com precipitação normal.

\section{Agradecimento}

À Fapesp, pelo apoio financeiro.

\section{Referências}

ALVARENGA, R.C.; LARA-CABEZAS, W.A.; CRUZ, J.C.; SANTANA, D.P. Plantas de cobertura de solo para sistema plantio direto. Informe Agropecuário, v.22, p.25-36, 2001.

AMABILE, R.F.; CORREIA, J.R.; FREITAS, P.L. de; BLANCANEAUX, P.; GAMALIEL, J. Efeito do manejo de adubos verdes na produção de mandioca (Manihot esculenta Crantz). Pesquisa Agropecuária Brasileira, v.29, p.1193-1199, 1994.

AMABILE, R.F.; FANCELLI, A.L.; CARVALHO, A.M. de. Comportamento de espécies de adubos verdes em diferentes épocas de semeadura e espaçamentos na região dos Cerrados, Pesquisa Agropecuária Brasileira, v.35, p.47-54, 2000.

ARF, O.; SILVA, L.S. da; BUZETTI, S.; ALVES, M.C.; SÁ, M.E. de; RODRIGUES, R.A.F.; HERNANDEZ, F.B.T. Efeitos na cultura do trigo da rotação com milho e adubos verdes, na presença e na ausência de adubação nitrogenada. Bragantia, v.58, p.323-334, 1999.

BANZATTO, D.A.; KRONKA, S.N. Experimentação agrícola. Jaboticabal: Funep, 1989. 247p.

BORTOLUZZI, E.C.; ELTZ, F.L. Efeito do manejo mecânico da palhada de aveia preta sobre a cobertura, temperatura, teor de água no solo e emergência da soja em sistema de plantio direto. Revista Brasileira de Ciência do Solo, v.24, p.449-457, 2000.

CENTURION, J.F.; DEMATTÊ, J.L.I. Efeitos de sistemas de preparo nas propriedades físicas de um solo sob cerrado cultivado com soja. Revista Brasileira de Ciência do Solo, v.9, p.263-266, 1985.

CERETTA, C.A.; AITA, C.; BRAIDA, J.A.; PAVINATO, A.; SALET, R.L. Fornecimento de nitrogênio por leguminosas na primavera para o milho em sucessão nos sistemas de cultivo mínimo e convencional. Revista Brasileira de Ciência do Solo, v.18, p.215220, 1994.

DE-POLLI, H.; CHADA, S. de S. Adubação verde incorporada ou em cobertura na produção de milho em solo de baixo potencial de produtividade. Revista Brasileira de Ciência do Solo, v.13, p.287293, 1989. 
EMBRAPA. Centro Nacional de Pesquisa de Solos (Rio de Janeiro, RJ). Sistema brasileiro de classificação dos solos. Brasília: Embrapa-SPI; Embrapa-CNPS, 1999. 412p.

FEHR, W.R.; CAVINESS, C.E. Stages of soybean development. Ames: Iowa State University, Cooperative Extension Service, 1977. 11p. (Special Report, 80).

HERNANI, L.C.; ENDRES, V.C.; PITOL, C.; SALTON, J.C. Adubos verdes de outono/inverno no Mato Grosso do Sul. Dourados: Embrapa-CPAO, 1995. 93p.

HERNANI, L.C.; SALTON, J.C.; FABRÍCIO, A.C.; DEDECEK, R.; ALVES JÚNIOR, A. Perdas por erosão e rendimentos de soja e trigo em diferentes sistemas de preparo de um Latossolo Roxo de Dourados (MS). Revista Brasileira de Ciência do Solo, v.21, p.667-676, 1997.

JOHNSON, J.F.; VOORHEES, W.B.; NELSON, W.W.; RANDALL, G.W. Soybean growth and yield as affected by surface and subsoil compaction. Agronomy Journal, v.82, p.973-979, 1990.

JOHNSON, L.F. Effect of the addition of organic amendments to soil on root knot of tomatoes: II. Relation of soil temperature, moisture, and pH. Phythopathology, v.52, p.410-413, 1962.

KIRKEGAARD, J.A.; SO, H.B.; TROEDSON, R.J. Effect of compaction on the growth of pigeon pea on clays soils. III. Effect of soil type and water regime on plant response. Soil and Tillage Research, v.26, p.163-178, 1993.

KLUTHCOUSKI, J.; FANCELLI, A.L.; DOURADO-NETO, D.; RIBEIRO, C.M.; FERRARO, L.A. Manejo do solo e o rendimento de soja, milho, feijão e arroz em plantio direto. Scientia Agricola, v.57, p.97-104, 2000.

LAL, R. Soil surface management in the tropics for intensive land use and high and sustained production. Advances in Soil Science, v.5, p.1-109, 1986.

LIMA, E.V. Alterações dos atributos químicos do solo e resposta da soja à cobertura vegetal e à calagem superficial na implantação do sistema de semeadura direta. 2001. 125p. Dissertação (Mestrado) - Universidade Estadual Paulista, Botucatu.

MARSCHNER, H. Mineral nutrition of higher plants. London: Academic Press, 1986. 403p.

MASCARENHAS, H.A.A.; NAGAI, V.; GALLO, P.B.; PEREIRA, J.C.V.N.A.; TANAKA, R.T. Sistemas de rotação de culturas de milho, algodão e soja e seu efeito sobre a produtividade. Bragantia, v.52, p.53-61, 1993.

MEDINA, P.F. Produção de sementes de cultivares precoces de soja, em diferentes épocas e locais do Estado de São Paulo. 1994. 173p. Tese (Doutorado) - Universidade de São Paulo, Piracicaba.
RAIJ, B. van; CANTARELLA, H.; QUAGGIO, J.A.; FURLANI, A.M.C. Recomendações de adubação e calagem para o Estado de São Paulo. 2.ed. Campinas: Instituto Agronômico, 1996. 285p. (Boletim Técnico, 100).

ROSOLEM, C.A.; ALMEIDA, A.C.S.; SACRAMENTO, L.V.S. Sistema radicular e nutrição da soja em função da compactação do solo. Bragantia, v.53, p.259-266, 1994.

SALTON, J.C.; MIELNICZUK, J. Relações entre sistemas de preparo, temperatura e umidade de um Podzólico Vermelho-Escuro de Eldorado de Sul (RS). Revista Brasileira de Ciência do Solo, v.19, p.313-319, 1995.

SANTOS, H.P. dos; TOMM, G.O.; LHAMBY, J.C.B. Plantio direto versus convencional: efeito na fertilidade do solo e no rendimento de grãos das culturas em rotação com cevada. Revista Brasileira de Ciência do Solo, v.19, p.449-454, 1995.

SILVA, R.H. da; ROSOLEM, C.A. Crescimento radicular de soja em razão da sucessão de cultivos e da compactação do solo. Pesquisa Agropecuária Brasileira, v.37, p.855-860, 2002.

SOUZA, C.M. Efeito do uso contínuo de grade pesada sobre algumas características físicas e químicas de um Latossolo Vermelho-Amarelo distrófico, fase cerrado, e sobre o desenvolvimento das plantas e absorção de nutrientes pela cultura de soja. 1988. 105p. Dissertação (Mestrado) - Universidade Federal de Viçosa, Viçosa.

STONE, L.F.; SILVEIRA, P.M. da. Efeito do sistema de preparo na compactação do solo, disponibilidade hídrica e comportamento do feijoeiro. Pesquisa Agropecuária Brasileira, v.34, p.83-91, 1999.

TANAKA, R.T.; MASCARENHAS, H.A.A.; DIAS, O.S.; CAMPIDELLI, C.; BULISANI, E.A. Cultivo da soja após incorporação de adubo verde e orgânico. Pesquisa Agropecuária Brasileira, v.27, p.1477-1483, 1992.

WANG, J.; HESKETH, J.D.; WOOLLEY, J.T. Preexisting channels and soybean rooting patterns. Soil Science, v.141, p.432-437, 1986.

WUTKE, E.B. Adubação verde: manejo da fitomassa e espécies utilizadas no Estado de São Paulo. In: WUTKE, E.B.; BULISANE, E.A.; MASCARENHAS, H.A.A. (Coord.). Curso sobre adubação verde no Instituto Agronômico. Campinas: Instituto Agronômico, 1993. p.17-29. (Documentos IAC, 35).

WUTKE, E.B.; FANCELLI, A.L.; PEREIRA, J.C.V.N.A.; AMBROSANO, G.M.B. Rendimento do feijoeiro irrigado em rotação com culturas graníferas e adubos verdes. Bragantia, v.57, p.325338, 1998.

YUSUF, R.I.; SIEMENS, J.C.; BULLOCK, D.G. Growth analysis of soybean under no-tillage and conventional tillage systems. Agronomy Journal, v.91, p.928-933, 1999.

Recebido em 16 de fevereiro de 2004 e aprovado em 9 de julho de 2004 